\title{
TAMAN SOSIAL DAAN MOGOT
}

\author{
Seandy Sebastian ${ }^{1)}$, Martin Halim ${ }^{2)}$ \\ 1)Program Studi S1 Arsitektur, Fakultas Teknik, Universitas Tarumanagara, Seandysebastian@gmail.com \\ 2) Program Studi S1 Arsitektur, Fakultas Teknik, Universitas Tarumanagara, martinhalim90@gmail.com
}

Masuk: 09-01-2020, revisi: 28-01-2020, diterima untuk diterbitkan: 09-05-2020 (doi: 10.24912/stupa.v2i1.6764)

\begin{abstract}
Abstrak
Seiring berjaannya waktu, budaya masyarakat yang terus berubah setiap waktu mengakibatkan perubahan pada berbagai macam aspek kehidupan terutama mengenai interaksi antar sesama. Kehidupan yang memiliki tingkat mobilitas yang cepat menyebabkan menurunnya interaksi antar manusia karena mereka harus selalu bergerak. Kejadian ini terjadi di kota - kota besar dan Jakarta adalah salah satunya. Kondisi ini dapat kita temui di perumahan kluster salah satunya adalah Perumahan Daan Mogot Baru dan Kalideres Permai, dimana interaksi antar tetangga sangatlah minim. Oleh karena itu dilakukanlah penelitian mengapa dan bagaimana masalah ini dapat diselesaikan melalui arsitektur. Penelitian ini dimulai dengan mengumpulkan data menggunakan 2 metode yaitu kuisioner dan obsevasi lingkungan sekitar batasan objek. Hasil data dari kuisioner yang berasal 40 responden yang berasal dari warga Perumahan Daan Mogot Baru dan Kalideres Permai membuktikan bahwa memang tingkat interaksi antar tetangga disana kurang. Salah satu penyebab utama kurangnya interaksi adalah kurangnya tempat / wadah untuk melakukan aktivitas bersama. Untuk membuat suatu wadah maka dibutuhkan program program yang akan menjadi kegiatan dalam wadah tersebut, berdasarkan data yang didapat dalam kuisioner program yang paling dibutuhkan adalah sarana olahraga. Namun sarana olahraga saja tidak akan bisa menyelesaikan masalah rendahnya interaksi di Perumahan Daan Mogot dan Kalideres Permai. Wadah tersebut harus dilengkapi dengan wadah untuk berinteraksi seperti tempat duduk untuk mengobrol dan bercengkrama serta tempat makan sehingga mereka memiliki alasan untuk tetap tinggal setelah mereka beraktivitas dan tercipta situasi yang mendukung untuk terjadinya interaksi.
\end{abstract}

Kata kunci: arsitektur; interaksi; open architecture

\begin{abstract}
As time goes by, the culture of society that continues to change every time resulted in changes in various aspects of life, especially regarding interactions between people. Life that has a fast level of mobility causes decreased interaction between humans because they must always move. This incident happened in big cities and Jakarta is one of them. This condition can be found in cluster housing, one of which is Daan Mogot Baru Housing and Kalideres Permai, where interaction between neighbors is minimal. Therefore, research is carried out why and how this problem can be solved through architecture. This study began by collecting data using 2 methods, namely questionnaire and observing the environment around the object boundaries. The results of the data from the questionnaire from 40 respondents who came from residents of Daan Mogot Baru and Kalideres Permai residents proved that the level of interaction between neighbors there was lacking. One of the main causes of the lack of interaction is the lack of place / place to do joint activities. To make a container, it takes a program that will be an activity in the container, based on the data obtained in the program questionnaire, the most needed is sports facilities. But sports facilities alone will not be able to solve the problem of low interactions in Daan Mogot Housing and Kalideres Permai. The container must be equipped with a container for interaction such as a place to sit and chat and have a place to eat so that they have a reason to stay after they move and create situations that support the occurrence of interaction.
\end{abstract}

Keywords: architecture, interaction; open architecture 


\section{PENDAHULUAN}

Arsitektur selalu berkembang mengikuti jaman setiap tahunnya. Namun arsitektur berkembang karena dirancang dan direncanakan bukan tumbuh dengan sendirinya. Arsitektur berkembang mengikuti budaya masyarakat yang terus berubah setiap waktu. Dalam merancang sebuah ruang tidak sembarang sebuah ruang terbentuk, mungkin ada beberapa catatan dalam membentuk sebuah ruang. Semakin kompleks suatu ruang dirancang semakin besar juga pengaruh terhadap penggunanya. Pada dasarnya manusia adalah mahluk sosial yang membutuhkan orang lain untuk bertahan hidup. Dengan berinteraksi dengan sesama, dapat membantu manusia mendapatkan rasa empati, kepedulian, daya nalar, proaktif dan hal-hal lain terhadap sesama manusia. Namun pada kenyataannya kehidupan di kota tidak sesimpel seperti kehidupan di desa. Masyarakat kota cenderung mencari hiburan atau bertemu dengan sesamanya di café atau di mall sehingga dengan banyaknya permintaan dan minat dari masyarakat, tempat komersial mulai menjamur di sepanjang titik perkotaan.

Dengan banyaknya tempat komersial seperti ini akan mengakibatkan hilangnya unsur interaksi pada sesama. Kejadian ini terjadi di kota - kota besar dan Jakarta adalah salah satunya. Kondisi ini dapat kita temui di perumahan kluster salah satunya adalah Perumahan Daan Mogot Baru dan Kalideres Permai, dimana interaksi antar tetangga sangatlah minim Namun masalah yang akan dibahas adalah apakah masyarakat sekarang membutuhkan dan masih ingin berinteraksi dengan sesama, apakah sebuah interaksi antar masyarakat hanya dapat dilakukan di tempat tertentu saja, serta apakah sebuah Third Place dapat memecahkan masalah kurangnya interaksi antar warga. Semoga dengan adanya proyek Third place ini Menyatukan masyarakat dengan berbagai latar belakang pada satu tempat untuk berbaur dan bersosialisasi tanpa adanya perbedaan derajat antar satu sama lain. Meningkatkan aktifitas warga Kalideres di luar rumah, serta menciptakan lingkungan yang lebih sehat bagi warga Perumahan Daan Mogot dan Kalideres Permai.

\section{KAJIAN LITERATUR}

\section{Open Architecture}

Menurut : Menurut Oldenburd (1997), 3rd place adalah tempat yang netral, tidak ada level diantara semua orang yang ada disana dengan arti mereka semua sederajat bila berada didalam sana. Kegiatan utama yang dilakukan disana adalah bersosialisasi dengan sesana dan tempat itu harus mudah diakses. $3^{\text {rd }}$ place juga adalah tempat yang biasa dan tidak spesial serta tidak mengada - ada. $3^{\text {rd }}$ place juga adalah tempat yang dapat membuat setiap orang merasa nyaman berasa disana. Sebuah komutitas membutuhkan sebuah $3^{\text {rd }}$ place.

\section{Open Society}

"Open society adalah konsep dimana masyarakat dapat hidup berdampingan dengan latar belakang yang berbeda beda, dengan menyepakati budaya secara bersama - sama. Hidup penuh toleransi dan pemikiran yang terbuka" Suryono Herlambang (2019). open society dimaksudkan untuk membuka segala kemungkinan dalam kehidupan bukan hanya yang baik saja namun yang buruk juga. Lingkungan yang tidak mengenal suku, ras, agama. Di Indonesia meskipun memiliki keberagaman dari segi suku, budaya, agama. Tetapi Indonesia belum bisa menerapkan open society pada sistem negaranya, karena masih banyak kekacauan dan itu nyata.

\section{Open City}

Open city adalah tempat dimana masyarakat dengan latar belakang yang berbeda - beda dapat hidup berdampingan. Open city hanya dapat diterapkan pada sebagian kecil saja di dalam kota dan letaknya harus menyebar. Sebuah kota tidak bisa menjadi open city seluruhnya karena akan menimbulkan kekacauan.

Arsitektur zaman sekarang terlalu fokus terhadap bentuk dan fungsi suatu bangunan, tetapi kurang memperhatikan siapa / pengguna yang akan tinggal disitu nantinya. Padahal bila suatu 
konsep suatu masyarakat sudah tertanam di benak masyarakat, bagaimanapun bentuk suatu Space maka akan bisa dijadikan suatu Place bagi mereka. Fungsi utama dari konsep open society berupa open city adalah membuka kembali konektifitas antar masyarakat yang sudah mulai hilang. Karena pada dasarnya manusia adalah mahluk sosial yang membutuhkan satu sama lain termasuk interaksi satu sama lain. Fungsi harus terbuka baik secara vertical maupun horizontal.

\section{Dwelling Space}

Dwelling space atau tempat untuk ditinggali adalah hal yang paling dibutuhkan oleh manusia sebagai suatu kebutuhan primer. Tetapi ternyata memikirkan suatu arti "rumah" bagi sebagian orang berbeda. Rumah dapat diartikan sebagai tempat dimana kita merasa nyaman dan aman sehingga kata "rumah" bisa berada dimana saya. Berikut beberapa contoh yang tipe Dwelling space menurut Agustinus Sutanto (2019).


Kegiatan sehari - hari

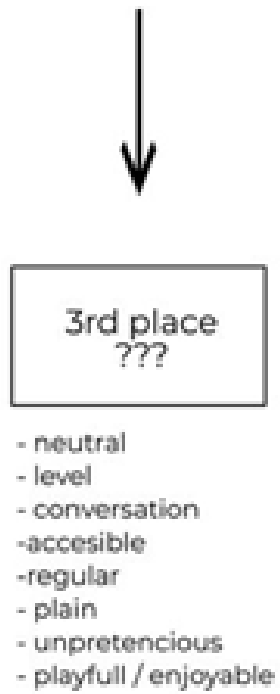

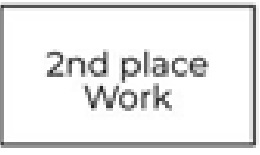

- employer - employee

- rigid

- structured

- sccial experiment

- formal

-organized

Gambar 1. Kriteria Third place

Sumber: Penulis, 2019

\section{METODE}

Dalam penelitian ini menggunakan tiga jenis metode pengumpulan data yaitu metode observasi, studi dokumen/literatur, kuisioner. Metode observasi lingkungan sekitar kawasan tapak perumahan Daan Mogot Baru untuk memahami lebih dalam kebiasaan dan kegiatan yang berlangsung disana. Studi dokumen /literatur berguna untuk mengetahui sifat-sifat dan kriteria dari sebuah Third place memilah beberapa unsur yang dapat diterima di kawasan. Serta metode kuisioner untuk mendapatkan data - data yang berhubungan dengan warga perumahan Daan Mogot Baru dan prumahan Kalideres permai sebagai target penelitian, untuk mendapatkan data-data yang berguna untuk menentukan program. 
- Observasi:

Mengamati langsung lokasi tapak dan lingkungan disekitar perumahan Daan Mogot baru dan perumahan Kalideres Permai.

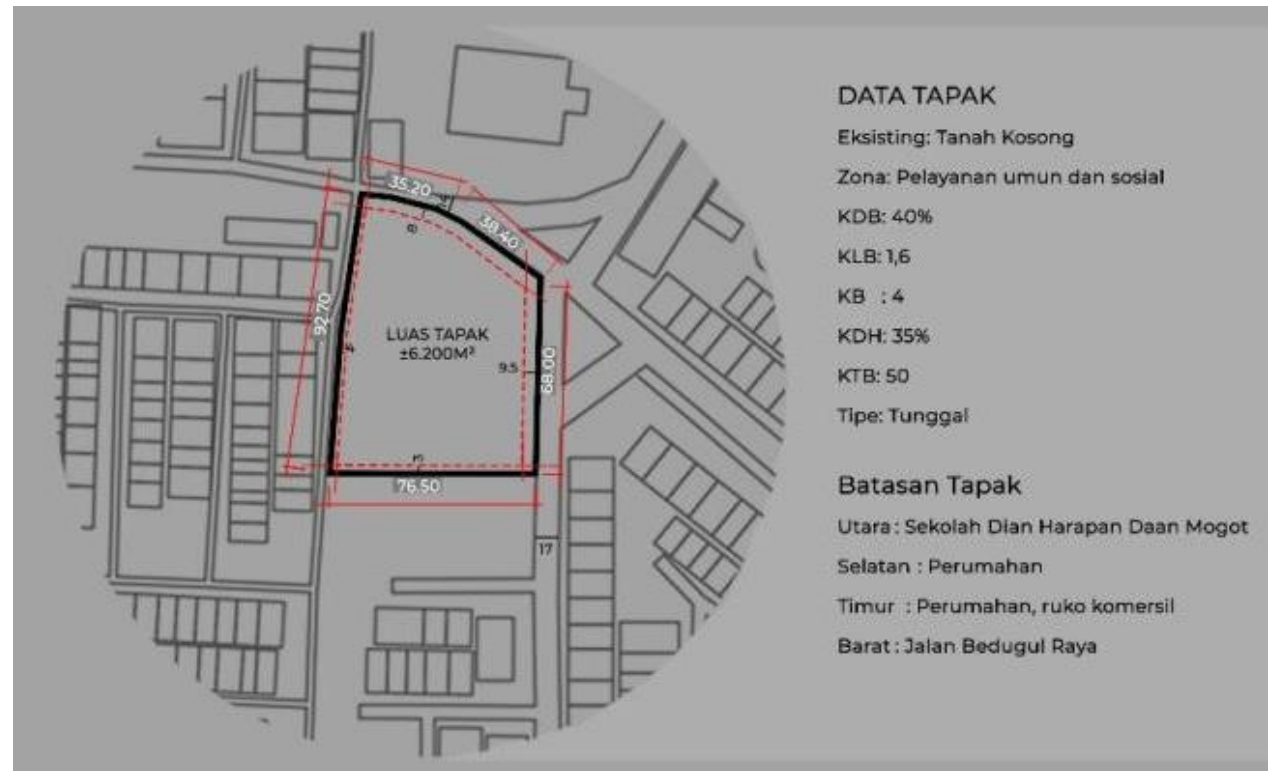

Gambar 2. Data tapak

Sumber: Penulis, 2019

- Studi dokumen/literatur:

Mempelajari kajian teori berdasarkan tema yang diberikan yaitu Open Architecture; Architecture for the Third Place, baik melewati media cetak ataupun online.

- Kuisioner:

Memberikan kuisioner kepada warga perumahan Daan Mogot Baru dan perumahan Kalideres permai sebagai target penelitian, untuk mendapatkan data - data yang berguna untuk menentukan program.

\section{Metode Analisa Data}

\section{Data kualitatif}

Manajemen data dimulai dari mencari kriteria dan sifat - sifat Third Place, lalu mengidentifikasikan isu yang ada di sekitar tapak terpilih. Setelah isu didapatkan dicarilah data - data untuk memperkuat sistem pemilihan program yang akan menyelesaikan masalah yang ada. Setelah data didapatkan, dimulailah menganalisa tapak terpilih lalu dituangkan menjadi sebuah text atau narasi. Data yang didapatkan nantinya akan direduksi sesuai dengan tema yang didapat yaitu Architecture for the Third Place, lalu data akan disajikan dalam bentuk naratif, grafik, diagram, dan gambar.

○ Data kuantitatif

- Scoring untuk pemilihan program

- Scoring untuk memilih tapak.

\section{Metode Perancangan proyek}

Tipologi: Dalam metode perancangan proyek ini, tipologi akan sangat membantu dalam merancang dari seri tipe bangunan menyangkut bangun dasar, sifat dasar, serta proses perkembangan bangun dasar tersebut sampai ke bentuk yang sekarang serta fungsi dari objek. 


\section{DISKUSI DAN HASIL}

Analisa tapak menggunakan sistem scoring untuk menentukan tapak terbaik untuk proyek ini.

Tabel 1. Scoring Tapak

\begin{tabular}{|c|c|c|}
\hline & Tapak Alternatif 1 & Tapak Alternatif 2 \\
\hline Lokasi & $=$ & \\
\hline Tapak & $\begin{array}{c}\text { Luas Tapak: } 8600 \mathrm{~m} 2 \\
(2)\end{array}$ & $\begin{array}{l}\text { Luas Tapak: } 8160 \mathrm{~m} 2 \\
\text { (2) }\end{array}$ \\
\hline peraturan & $\begin{array}{ll}\text { - Zona: Pelayanan umun dan } \\
\text { - } \\
\text { - } \mathrm{KDB}: 40 \\
\text { - } \mathrm{KLB}: 1,6 \\
\text { - } \mathrm{KB}: 4 \\
\text { - } \mathrm{KDH}: 35 \\
\text { - } \mathrm{KTB}: 50 \\
\text { Tipe: Tunggal }\end{array}$ & $\begin{array}{l}\text { - Zona: Perumahan sedang } \\
\text { - tinggi } \\
\text { - } \text { KDB: } 60 \\
\text { - KLB: } 1,2 \\
\text { - KB : } 2 \\
\text { - KDH: } 20 \\
\text { - KTB: } 0 \\
\text { - } \quad \text { Tipe : D }\end{array}$ \\
\hline
\end{tabular}

(2)

- Berada di nodes antara perempatan

Jalan

- Berada di jalan sekunder Jl.Bedugul Raya

- Berada di jalan menuju pintu perbatasan diantara perumahan Daan Mogot Baru dan Kalideres Permai.

(3)

(3)

- Terminal Kalideres (500m)

- Halte Transjakarta Kalideres (500m)

Akses

- Halte Transjakarta Pesakih $(1 \mathrm{~km})$

- Akses ke jalan arteri, Jl. Daan Mogot (1km)

(3) (11)
- Seluruh tapak dikelilingi oleh jalan yang memudahkan akses.

- Berada pada jalan sekunder Jl. Utan Jati.

Sumber: Penulis, 2019

Berdasarkan hasil scoring tapak dari 2 alternatif tapak yang ada, tapak terpilih berada di Jalan Bedugul Raya, Kelurahan Kalideres, Kecamatan Kalideres, Jakarta Barat. 


\section{Data Tapak}

- Luas Tapak: $8600 \mathrm{~m} 2$

- Zona: Pelayanan umun dan sosial

- KDB: 40

- KLB: 1,6

- $\mathrm{KB}: 4$

- KDH: 35

- KTB: 50

- Tipe: Tunggal

Batasan Tapak

- Utara: Sekolah Dian Harapan Daan Mogot

- Selatan: Perumahan

- Timur: Perumahan, ruko komersil

- Barat: Jalan Bedugul Raya

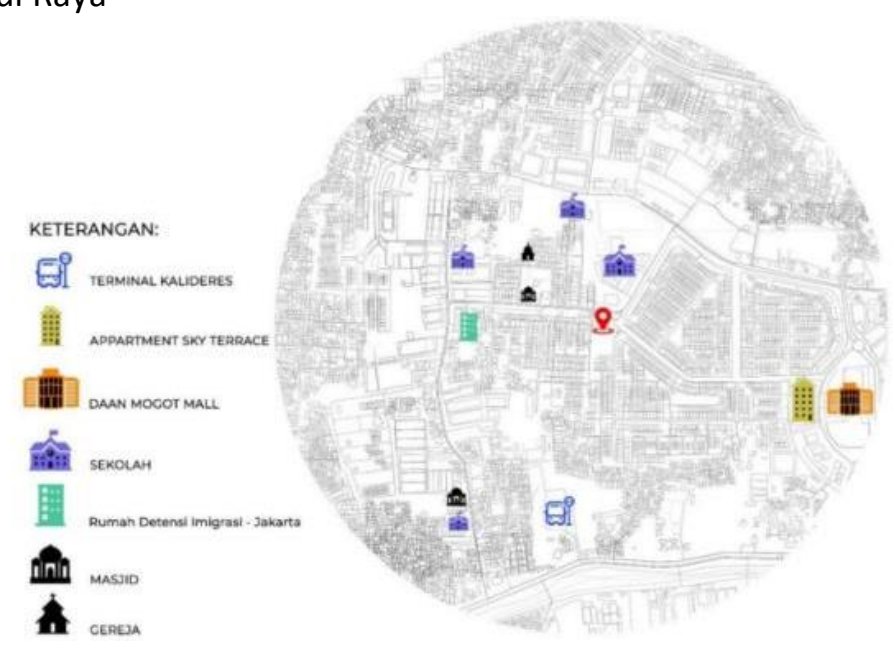

Gambar 3. Surrounding Development

Sumber: Penulis, 2019

Analisa daerah di sekitar Tapak kawasan memperlihatkan adanya bangunan ibadah Masjid dan Gereja yang berdekatan yang menunjukkan bahwa masyarakat yang tinggal disini bersifat heterogen.
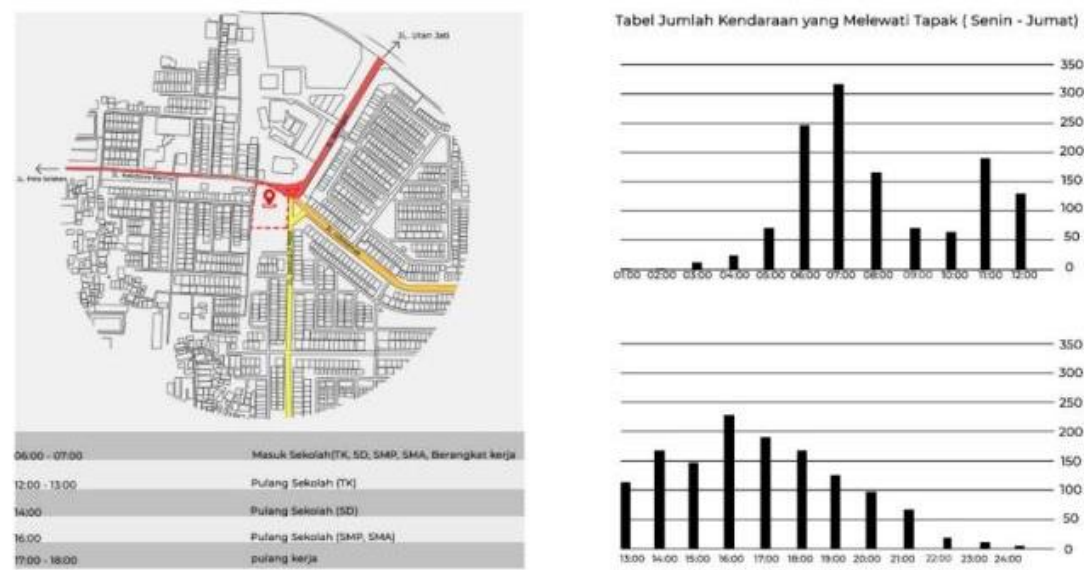

Gambar 4 Surrounding Activity

Sumber: Penulis, 2019 
Data jumlah kendaraan yang melewat kawasan juga menunjukkan bahwa Sekolah Dian Harapan yang berada di tapak memainkan peran penting didalam pusat aktivitas kawasan. Dapat dilihat bahwa kepadatan terjadi tepat di jalan akses keluar masuk sekolah dan kepadatan kendaraan terjadi di saat jam masuk dan pulang sekolah. Berikut adalah data - data hasil dari kuisioner yang dibagikan pada 40 responden yang adalah warga Perumahan Daan Mogot Baru dan Kalideres Permai.

Tabel 2. Data Kriteria Program


Sumber: Penulis, 2019

Berdasarkan hasil data yang didapat dari kuisioner warga setempat, kriteria - kriteria tempat yang dapat meningkatkan interaksi warga adalah sebagai berikut:

- Aktifitas diluar rumah seperti olahraga, bermain, dll (67.3\%)

- Meliki kepentingan / kebutuhan (63.5\%)

- Organisasi keagamaan, sekolah, lingkungan (44.2\%)

- Tempat kerja yang sama (17.3\%)

Berdasarkan kriteria program yang didapat maka dilakukanlah pemilihan program - program yang memiliki fungsi - fungsi sesuai dengan apa yang dibutuhkan warga kluster serta program yang dapat membuat aktifitas warga kluster meningkat seperti berolahraga dan bermain. Program - program berikut adalah program yang dipilih berdasarkan analisa dan survey lapangan secara langsung. Program yang diusulkan ini belum ada di kawasan tapak terpilih serta dinilai akan meningkatkan aktifitas dan memenuhi kebutuhan warga sehingga bisa meningkatkan interaksi antar warga kluster.

Tabel 3. Data Hasil pemilihan Program Bila anda diberikan pilihan, fasilitas manakah yang belum ada dan anda butuhkan di kawasan tempat tinggal anda agar interaksi disana meningkat.

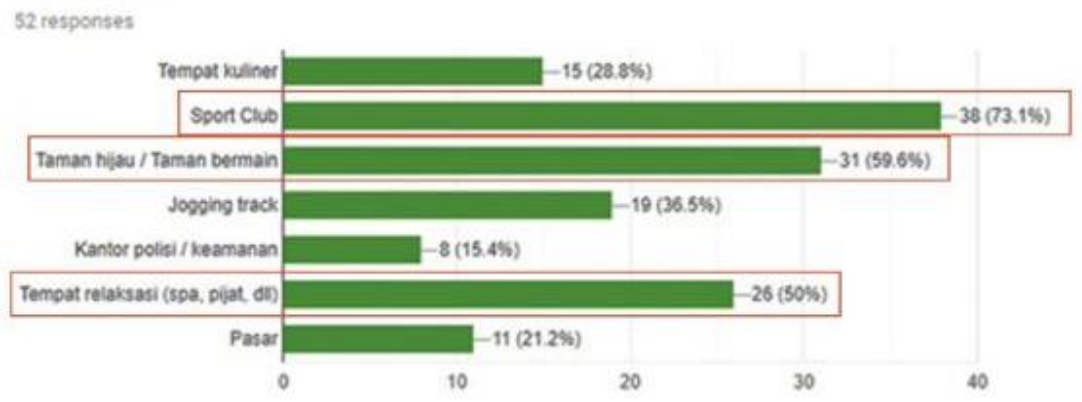

Sumber: Penulis, 2019 
Berdasarkan hasil data yang didapat dari kuisioner warga setempat, program yang diyakini diinginkan oleh warga kluster Daan Mogot Baru dan Kalideres permai adalah sebagai berikut:

- $\quad$ Sport Center (73.1\%)

- Taman hijau / taman bermain ( 59.6\%)

- Tempat relaksasi (50\%)

- Jogging track (36.5\%)

- Tempat kuliner (28.8\%)

- Pasar (21.2\%)

- $\quad$ Kantor polisi (15.4\%)

Program yang diusulkan adalah program yang didasarkan oleh data kuisioner kebutuhan dan fasilitas yang dibutuhkan oleh warga perumahan Daan Mogot baru dan Kalideres Permai. Program yang diambil adalah program yang mendapat suara sebanyak $50 \%$ atau lebih, program yang terpilih dari survei kuisioner adalah sebagai berikut:

- Sport Center

- Taman hijau / taman bermain

- Tempat relaksasi

\section{Program Usulan Berdasarkan Survey dan Analisa Lingkungan}

Berdasarkan pengamatan dan analisa lingkungan sekitar tapak, maka disimpulkan beberapa program yang tidak termasuk dalam kriteria data namun program dibutuhkan karena banyaknya kegiatan yang mendukung program tersebut di kawasan sekitar tapak. Program yang diusulkan adalah sebagai berikut.

\section{Study Center}

Luasan program

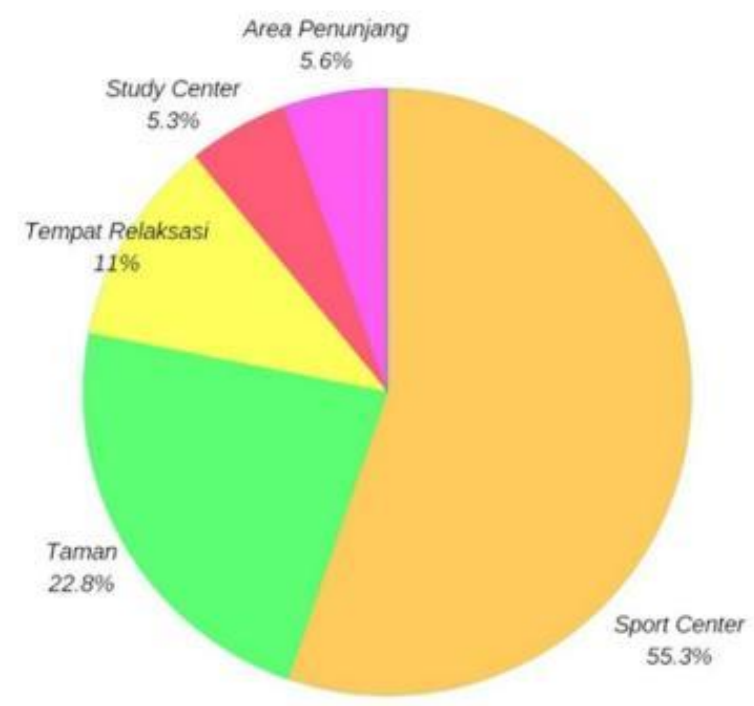

Gambar 5. Pembagian Luasan Program Sumber: Penulis, 2019

Berikut adalah besaran program yang nantinya akan dirancang, luasan program ditentukan berdasarkan prioritas yang dibutuhkan. Jenis - jenis program dibagi menjadi tiga bagian yaitu, program utama (sport Center, Taman hijau / bermain, Tempat relaksasi) adalah program yang dipilih berdasarkan keinginan dari warga perumahan Daan Mogot Baru dan Kalideres permai itu sendiri. Lalu yang kedua adalah secondary program (Study center) yang dibutuhkan dan dipilih berdasarkan analisa dan pengamatan lapangan secara langsung. Yang ketiga adalah program yang akan menunjang keberlangsungan projek. 


\section{Program Utama}

- Sport Center atau pusat olahraga adalah hal yang sudah wajib ada didalam perumahan kluster. Pusat olahraga menyediakan berbagai fasilitas dan program acara yang beraneka ragam tergantung dari permintaan dan acara yang dibuat oleh pengelola. Fasilitas yang disediakan antara lain seperti kolam renang, lapangan basket, lapangan bulu tangkis, lapangan futsal, ruang kaca. Sedangkan program acara yang biasanya rutin dilakukan adalah senam, yoga, dll.

- Taman hijau / nermain merupakan wadah bagi warga cluster yang sudah jenuh dengan pemandangan rumah - rumah yang monoton. Berbagai kegiatan juga dapat dilakukan disini seperti Jogging, bercengkrama.

- Tempat relaksasi menyediakan fasilitas - fasilitas seperti spa, pijat, tempat meditasi. Tempat ini ditargetkan untuk para orang tua yang lelah sehabis pulang bekerja dan ingin beristihat meringankan tubuh.

\section{Program Sekunder}

- Study center, lokasi tapak berada sangat dengan dengan fasilitas Sekolah Dian Harapan Daan Mogot yang rata - rata murid yang bersekolah disana tinggal pada perumahan Daan Mogot Baru dan Kalideres permai. Pada beberapa titik juga ditemukan tempat les bimbel yang letaknya tidak saling berjauhan. Dengan adanya study center, seluruh tempat les dapat ditampung dalam satu tempat sehingga mempermudah mereka baik anak - anak yang akan menggunakan fasilitas yang disediakan disana dan orang tua mereka dalam mengawasi anak mereka.

\section{Program Penunjang dan Servis}

Area penunjang seperti multifuncion roo, tempat membeli makanan, dan mini market juga harus disediakan untuk menunjang jalannya projek ini. Selain itu tempat - tempat kantor seperti kantor pengelola dan area servis juga akan berperan penting dalan keberlangsungan projek ini.

\section{Design Scheme}
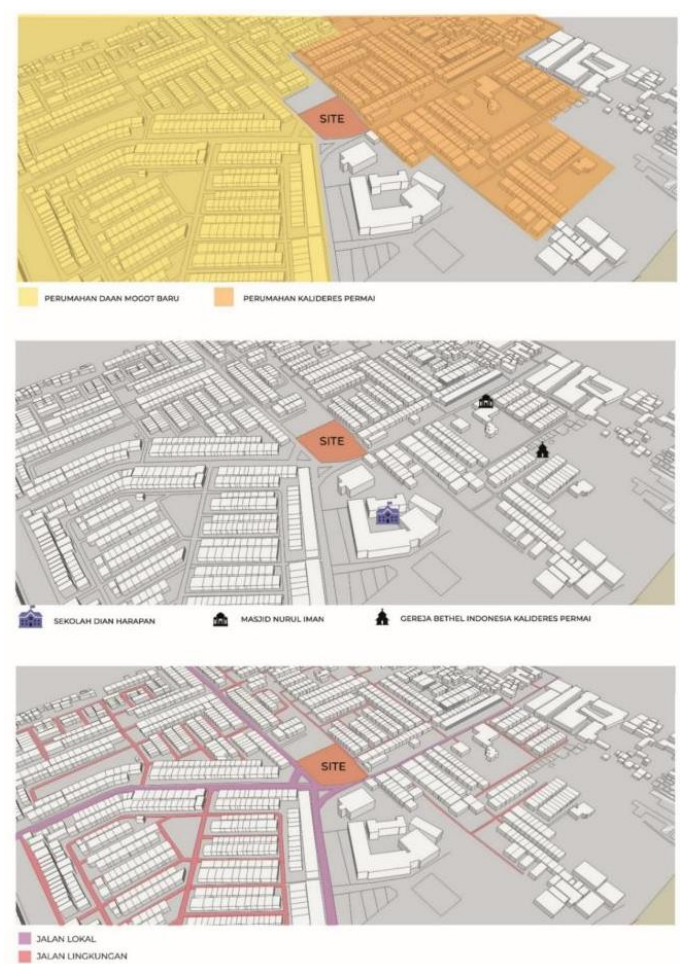

Gambar 6. Site Analysis

Sumber: Penulis, 2019 

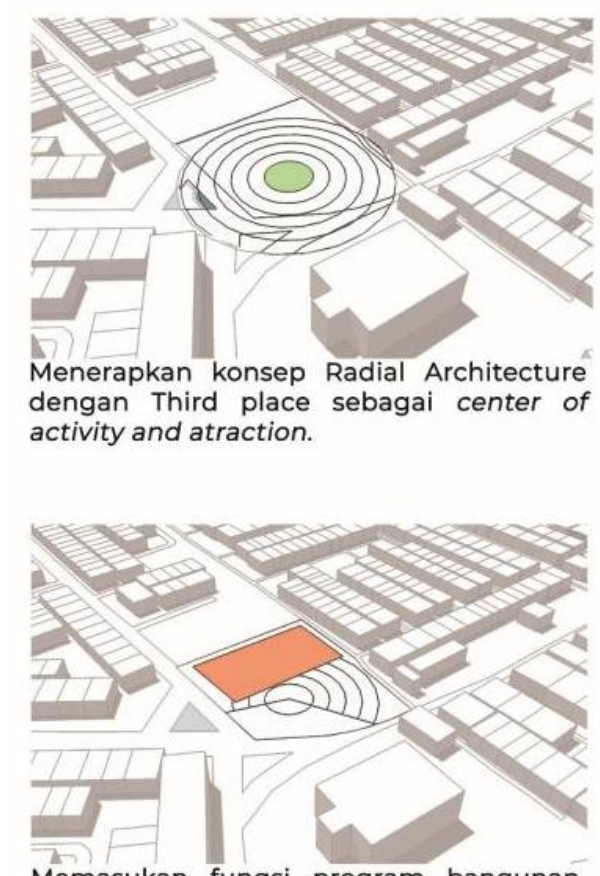

Memasukan yang membutuhkan tipologi khusus yaitu lapangan - lapangan olahraga.



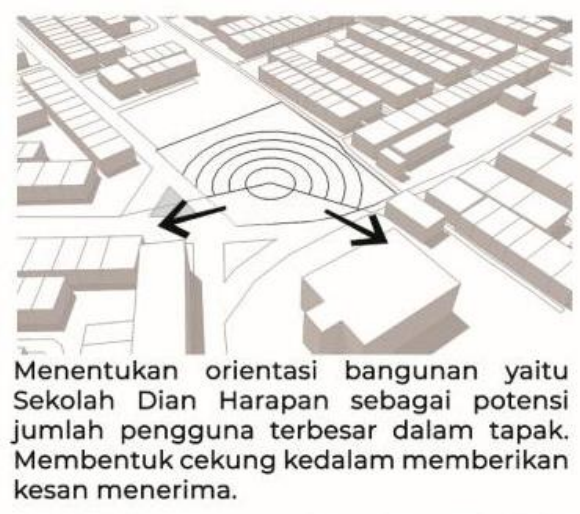

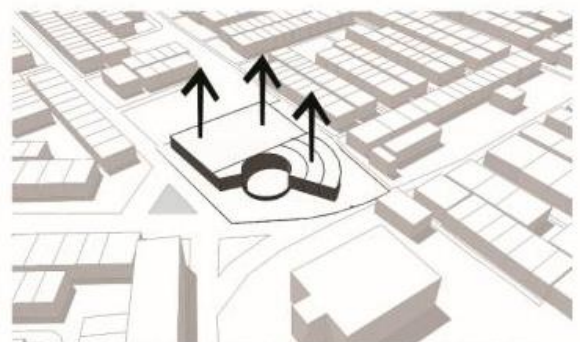

Membuat massa bangunan menyesuaikan kebutuhan serta luasan program.



Membuka massa yang menghalangi axis jalan sehingga massa terkesan menerima.

Gambar 7. Massing Process

Sumber: Penulis, 2019

\section{Konsep Design}

KONSEP DESIGN - Radial Architecture

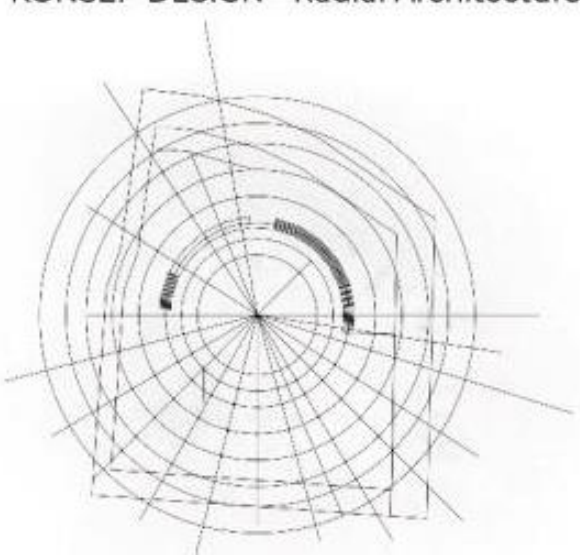

KONSEP DESIGN - TIPOLOGI
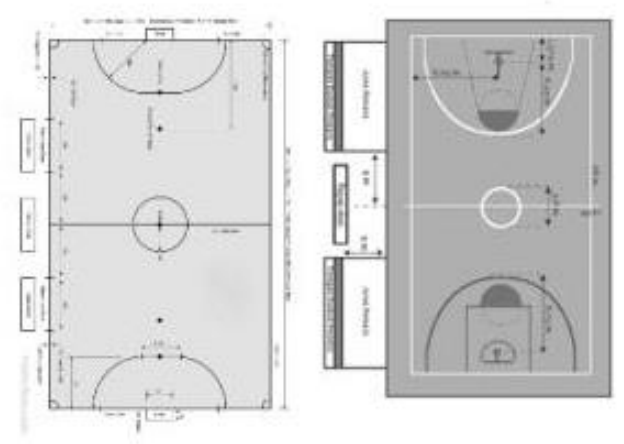

Gambar 8. Konsep design

Sumber: Penulis, 2019 
Lingkaran adalah sesuatu bentuk yang terpusat, berorientasi kedalam dan pada umumnya bersifat stabil dan dengan sendirinya menjadi pusat dari lingkungannya. Penempatan sebuah lingkatan pada pusat suatu bidang akan memperkuat sifat dasarnya sebagai poros. Menempatkan garis lurus atau bentuk - bentuk bersudut lainnya disekitar bentuk lingkaran atau menempatkan suatu poros kearah kelilingnya dapat menimbulkan perasaan gerak putar yang kuat. Komposisi dari lingkaran bisa mencapai titik:

- Netral

- Stabil

- Seimbang

- Terpusat

- Dinamis

Tipologi lapangan rata - rata memiliki bentuk persegi panjang serta membutuhkan ruang gerak bebas samping yang cukup besar.

\section{PENGGABUNGAN TIPOLOGI 3RD PLACE DAN TIPOLOGI LAPANGAN}
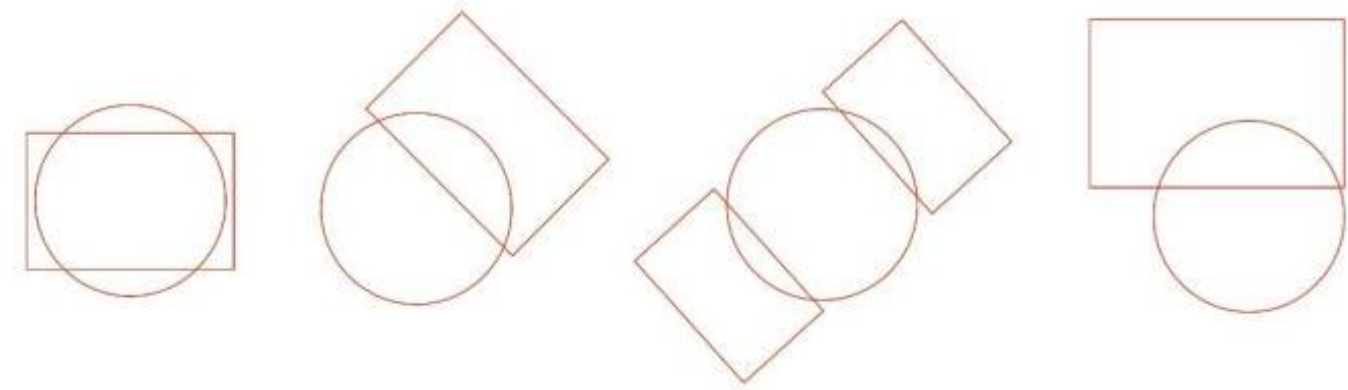

Gambar 9. Combining tipology

Sumber: Penulis, 2019

Menggabungkan dua bentuk yang memiliki dua sikap yang berbeda merupakan hal yang sulit namun bukan suatu hal yang tidak mungkin dilakukan. Dengan beberapa percobaan dan berbagai perhitungan akan didapatkan bentuk yang harmonis hasl penggabungan bentuk lingkaran dan persegi panjang.

\section{Perpektif}

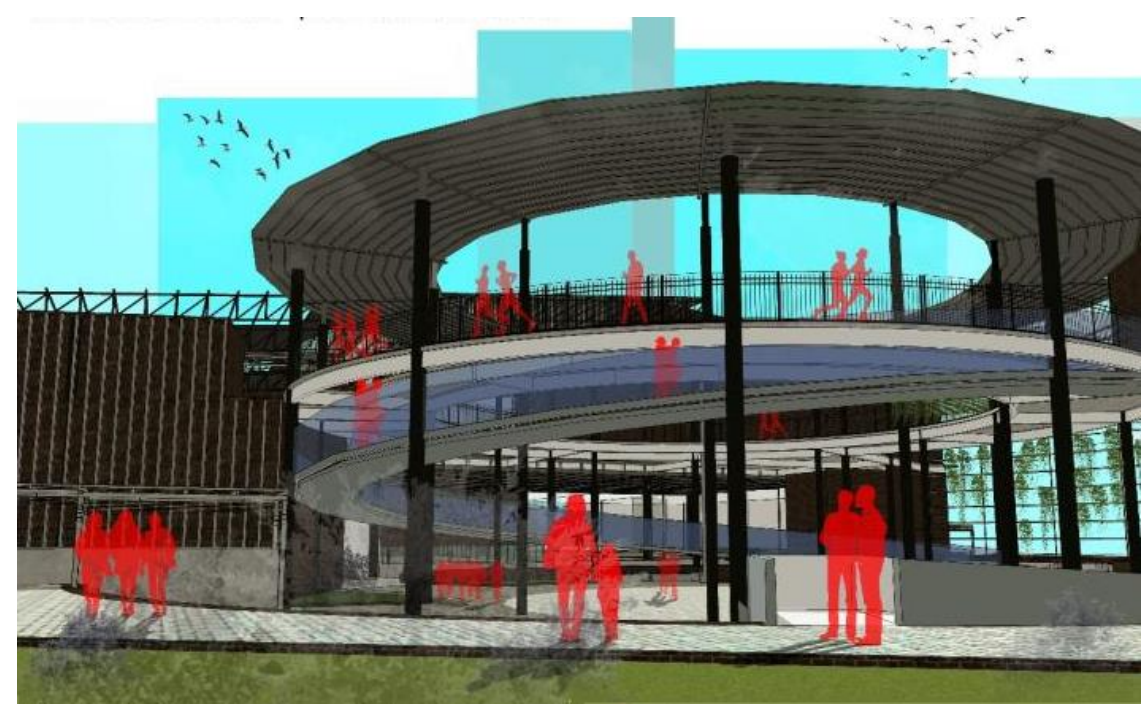

Gambar 10. Perspektif human eye view Sumber: Penulis, 2019 
Bentuk lingkaran menggambarkan bentuk yang netral sehingga menimbulkan kesan nyaman dan tidak memihak siapapun, sangat cocok ditempatkan didalam lingkungan yang bersifat heterogen. Ini membuat bangunan memiliki sifat menerima semua golongan masyarakat tanpa memandang siapa mereka.
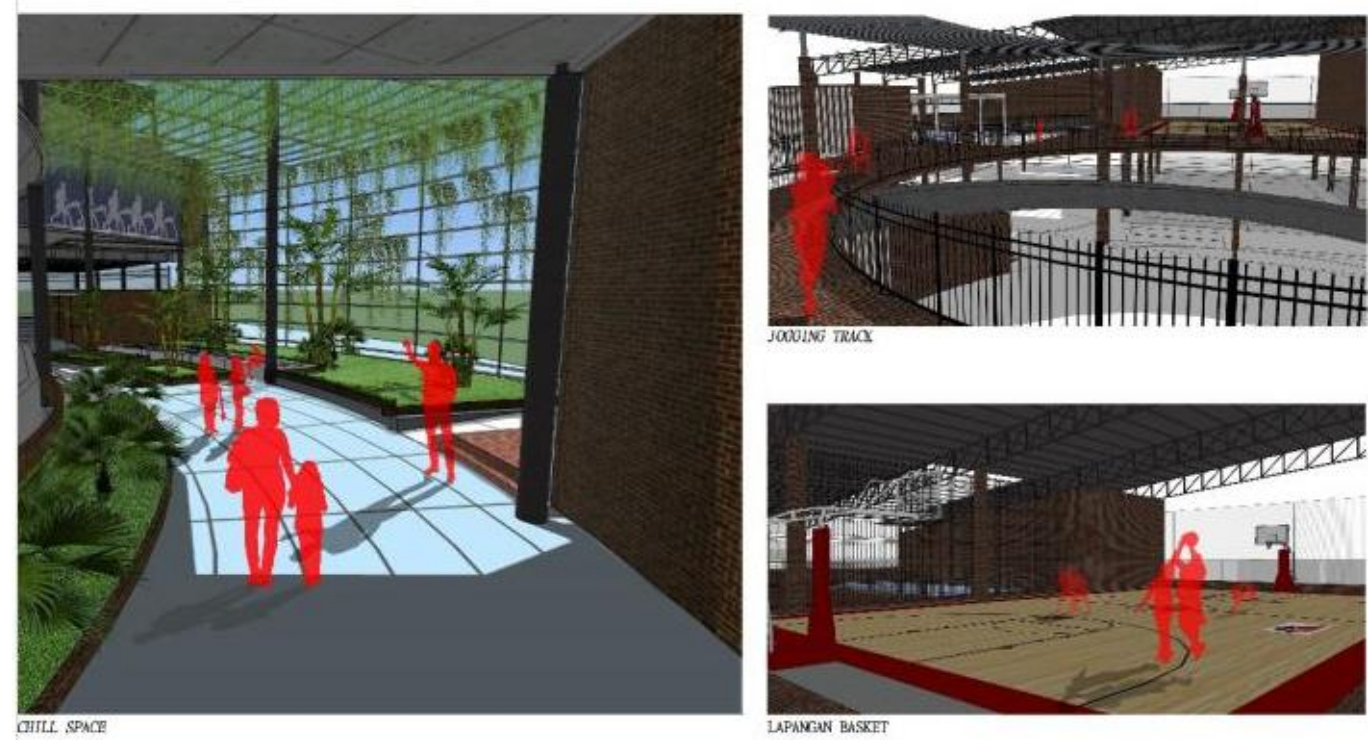

Gambar 11. Perspektif interior

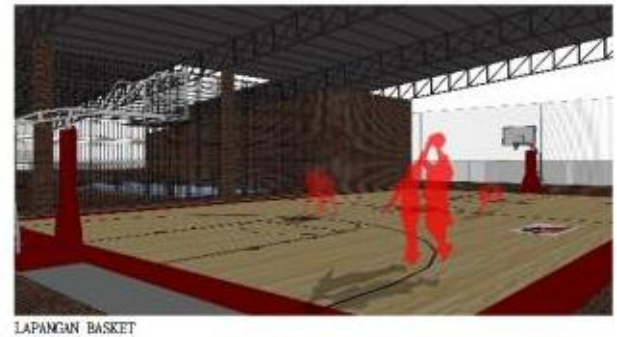

Sumber: Penulis, 2019

Ruang interior bangunan dibuat seterbuka mungkin dengan memanfaatkan pencahayaan dan pengudaraan alami yang akan membuat bangunan ini hemat energi. Sirkulasi didesign sedemikian rupa sehingga minimnya bentuk menyudut. Ini menimbulkan kesan luas dan tidak ada habisnya.

\section{KESIMPULAN DAN SARAN}

Kurangnya interaksi antar warga di Perumahan Daan Mogot Baru dan Kalideres permai disebabkan oleh kurangnya wadah / tempat untuk bekegiatan yang memacu terjadinya sebuah interaksi. Kurangnya sarana - sarana aktifitas seperti sarana olahraga, kuliner, taman, dsb. Tempat dimana mereka dapat beraktivitas bersama dan dapat bertemu dengan wajah - wajah baru yang mungkin selama ini belum mereka kenal meski mereka tinggal berdekatan.

Oleh karena itu haruslah disediakan wadah yang menyediakan wadah sarana berkegiatan yang memacu terjadinya suatu interaksi serta tidak lupa menambahkan tempat - tempat duduk untuk bercengkrama dengan kondisi yang nyaman dan mendukung untuk terjadinya sebuah interaksi. Sehingga tingkat interaksi antar warga perumahan Daan Mogot baru dan Kalideres permai dapat meningkat.

\section{REFERENSI}

Bertisch S.M., dkk., (2012). "Use of Relaxation Techniques and Complementary and Alternative Medicine by American Adults with Insomnia Symptoms: Results from a National Survery", J Clin Sleep Med

Heidegger, M. (1971). Building Dwelling Thinking: Harper Colophon. Books: New York. Herlambang, S. (2019). Open Society Open City Open Architecture. Diktat Stupa 8 Oldenburg, R. (1989). The Great Good Place. New York: Paragon House.

Sutanto, A. (2019). Architecture of The Third Place. Diktat Stupa 8

Winata, S. (2019). Open Architecture as The Third Place Architecture. Diktat Stupa 8 